\title{
Rompiendo paradigmas en la observación microscópica Comunicación Preliminar
}

\author{
RITO ZERPA \\ Instituto de Medicina Tropical "Daniel A. Carrión”-UNMSM. \\ Instituto Especializado de Salud del Niño.
}

\begin{abstract}
Las observaciones microscópicas de los microorganismos, como bacterias, suelen hacerse con objetivos de mayor aumento y de inmersión. Las fotomicrografías con aquellos microscopios que tienen incorporada una cámara fotográfica, permiten usualmente visualizar los microorganismos en dos planos y las imágenes generalmente a 1000 aumentos. Éstas se encuentran principalmente en un atlas o como fotografías sueltas ilustrando manuales. Las imágenes a más de 1000 aumentos suelen requerir el uso de microscopios electrónicos de transmisión o de barrido (scanning). Con este último se obtiene imágenes tridimensionales, en muchos casos de gran ayuda para el mejor conocimiento de los microorganismos. El objetivo de la presente comunicación preliminar es presentar fotomicrografías de organismos -bacterias, hongos, parásitos y un caso de infección por virus- en una nueva visión, con imágenes muchas de ellas a más de 1000 aumentos (entre 5000 y 15000 aumentos), sin necesidad del microscopio electrónico de transmisión o de barrido. Se ha recolectado imágenes de casos o patologías diversas presentadas en niños atendidos en el Instituto de Salud del Niño en los últimos 5 años. Las imágenes obtenidas de cada caso utilizando un microscopio común son producto de varios trabajos, como el de Bartonella bacilliformis para visualizar sus flagelos, Corynebacterium diphtheriae o el de neumococo con su cápsula; asimismo de los hongos Cryptococcus neoformans, Paracoccidioides brasiliensis o artrosporas de un dermatofito; y de algunos parásitos de importancia médica en imágenes tridimensionales, tales como Cyclospora cayetanensis, Blastocystis hominis y Strongyloides stercoralis (larva rhabditoide y huevo), éstos a más de 1000 aumentos y en tridimensión. Las imágenes son presentadas en las fotomicrografías adjuntas. Las imágenes o fotomicrografías presentadas, de microorganismos como bacterias, hongos y parásitos, muchas de ellas a más de 1000 aumentos (algunas entre 5,000, 10,000 y 15,000 aumentos), e imágenes tridimensionales como las obtenidas con microscopio electrónico de barrido, tienen un gran potencial para el diagnóstico microbiológico, la docencia e investigación. Se ha roto los paradigmas de obtener imágenes de microorganismos bidimensionales y tridimensionales a más de 1000 aumentos sin recurrir al uso del microscopio electrónico de transmisión ni al de barrido (scanning).
\end{abstract}

\section{BIBLIOGRAFÍA}

1. Koneman EW, Allen SD, Janda WM, Schrereckenberger PC, Winn WC. Color Atlas and Textbook of Diagnostic Microbiology. $5^{\text {th }}$ Edition. Lippincott, 1997.
2. Murray PR, Baron EJ, Pfaller MA, Tenover FC, Yolken RH. Manual of Clinical Microbiology. $7^{\text {th }}$ Edition, Washington D.C.: ASM PRESS; 1999.

3. Garcia LS, Bruckner DA: Diagnostic Medical Parasitology. 2nd Edition, Washington D.C.: ASM; 1993.

\footnotetext{
Correspondencia:

Dr. Rito Zerpa Larrauri

Instituto de Medicina Tropical "Daniel A. Carrión"

UNMSM - Sección de Microbiología.

Jr. José Santos Chocano 199. Urb. San Joaquín

Callao 02, Perú

E-mail:rzerpa43@hotmail.com
} 


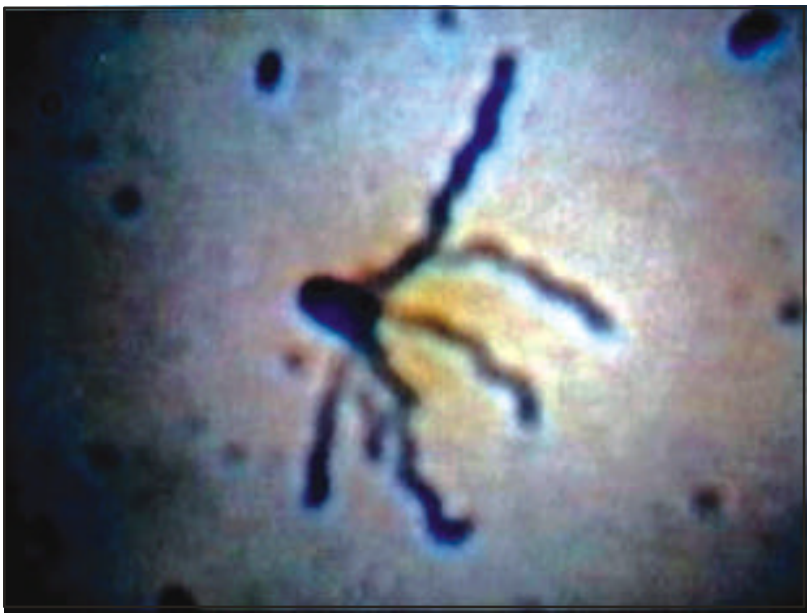

Figura 1.-Bartonella bacilliformis:

Agente etiológico de la bartonelosis o Enfermedad de Carrión; tinción de Kodaka modificado.

Se observa al microorganismo con varios flagelos en un polo.

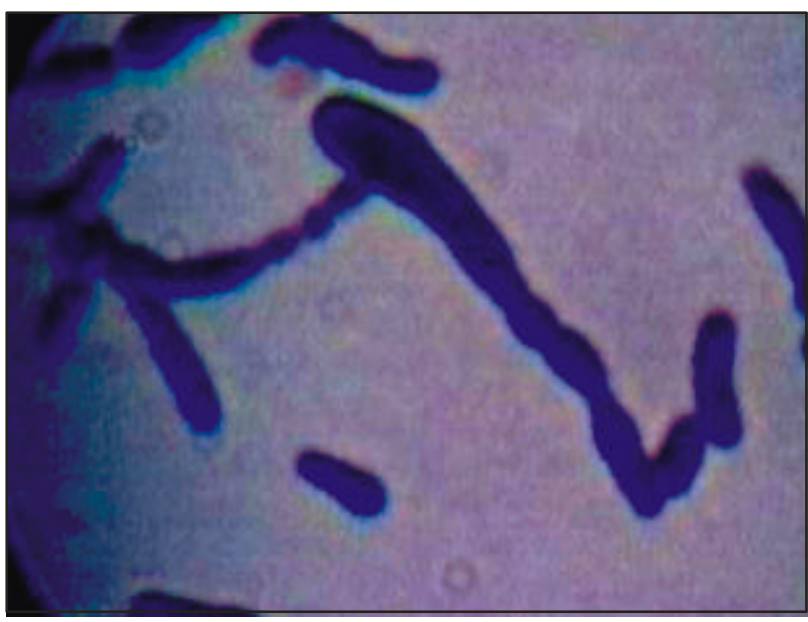

Figura 3.-Corynebacterium diphtheriae:

Agente etiológico de la difteria; tinción de Gram; la bacteria Gram positiva se observa agrupada en forma de letras chinas.

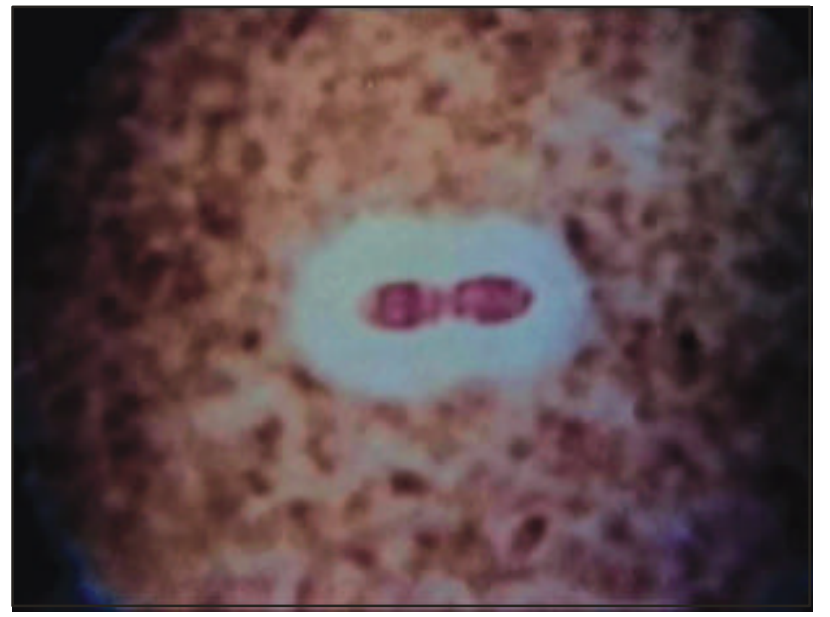

Figura 2.-Streptococcus pneumoniae

(neumococo): tinción con la "Técnica de tinta china modificada". Se observa al diplococo lanceolado rodeado de cápsula.

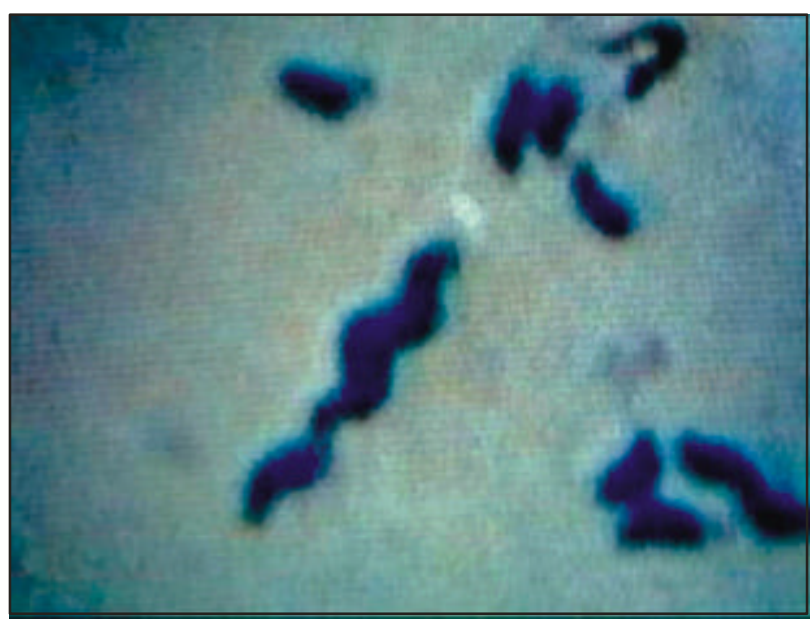

Figura 4.- Campylobacter jejuni:

Agente etiológico de diarrea en el hombre, tinción de Vago. Se visualiza al microorganismo curvado en forma espirilar. 


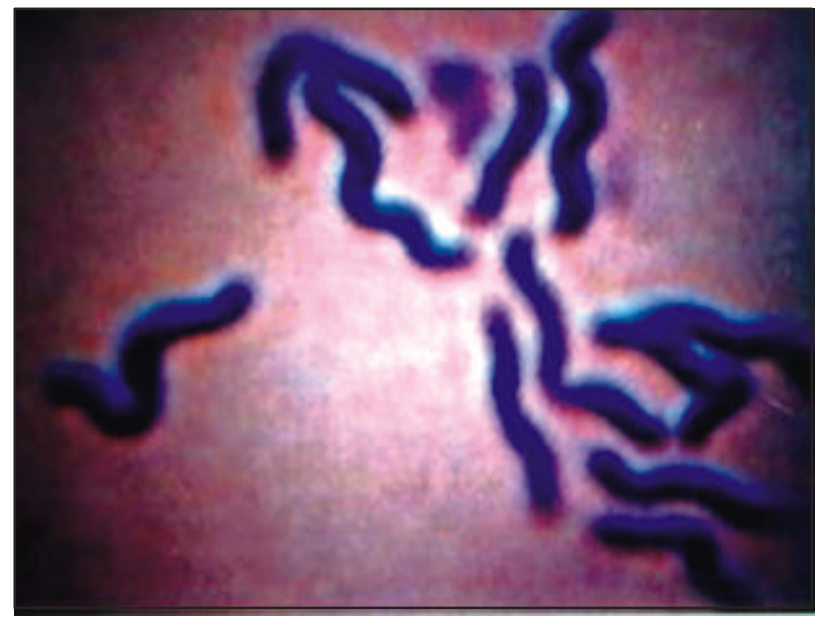

Figura 5.-Helicobacter pylori:

Se encuentra asociado a cuadros de gastritis, úlcera gástrica, úlcera duodenal; tinción de Vago. Se visualiza formas curvadas de la bacteria.

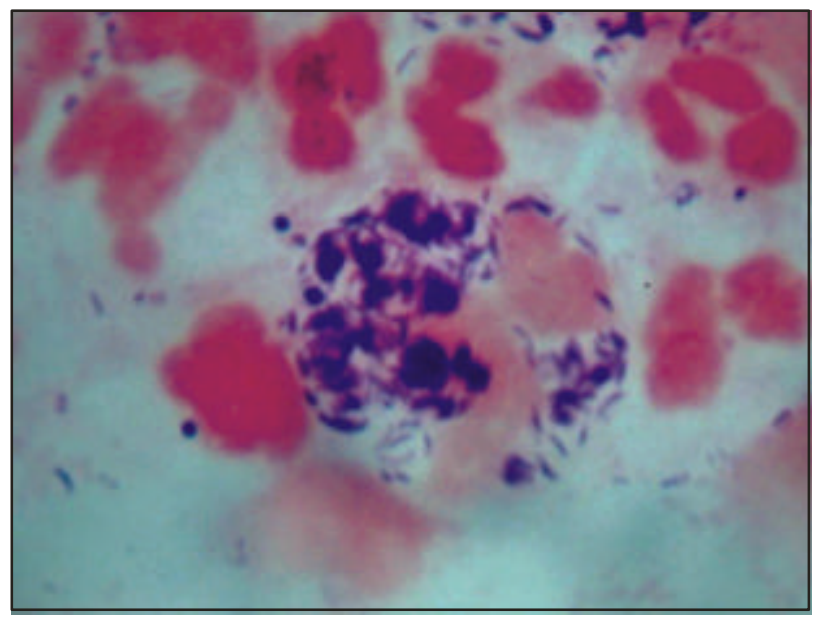

Figura 7.-Mobiluncus sp:

Fagocitado por un leucocito; tinción de Gram. Se observa gran número de bacterias fagocitadas, en el caso de una niña con vulvovaginitis.

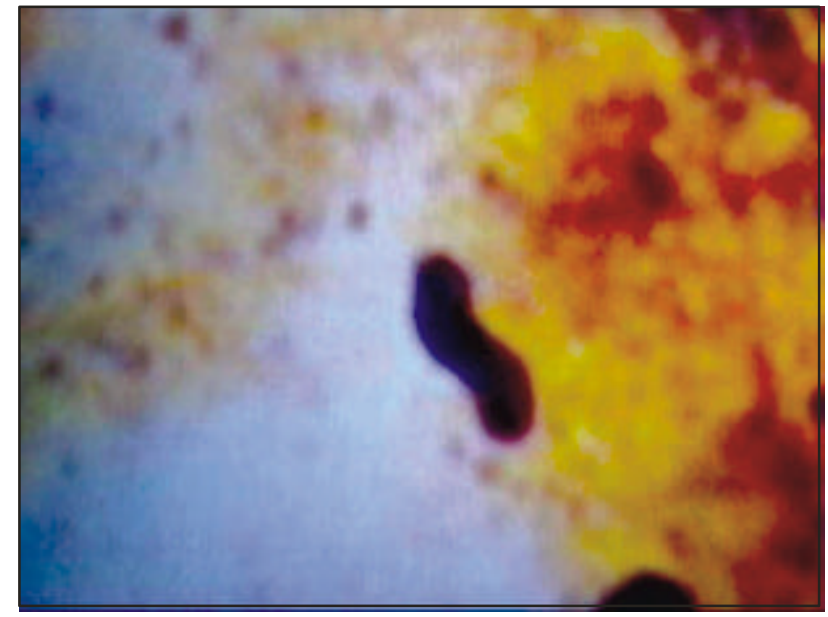

Figura 6.-Helicobacter pylori:

En preparación a partir de biopsia de estómago. Tinción de Wartin Starry; se visualiza a la bacteria en forma curvada en S.

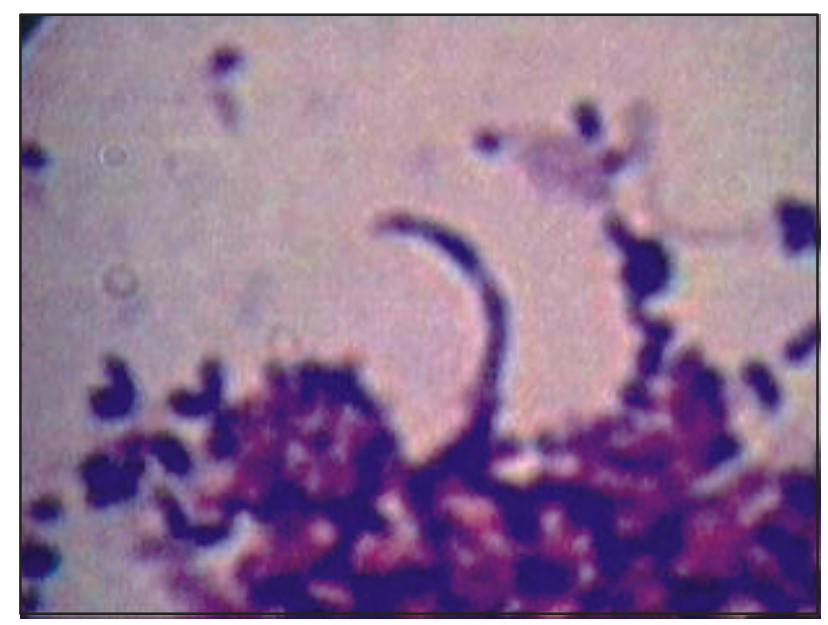

Figura 8.-Mobiluncus sp:

En un frotis de secreción vaginal de una adolescente con vaginosis bacteriana. 


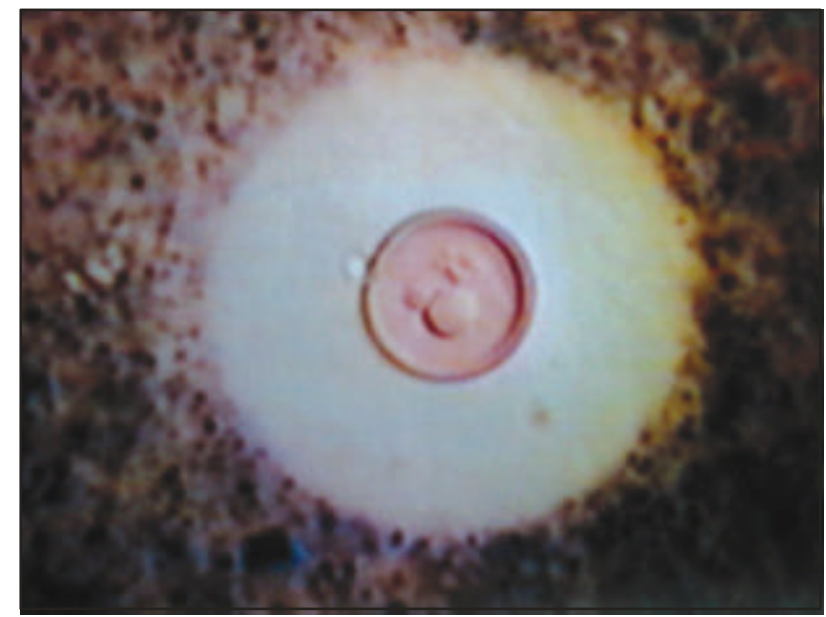

Figura 9.- Cryptococcus neoformans:

Agente etiológico de meningitis, principalmente en pacientes inmunodeprimidos; tinción de "tinta china modificada". Se visualiza al hongo con una gran cápsula.

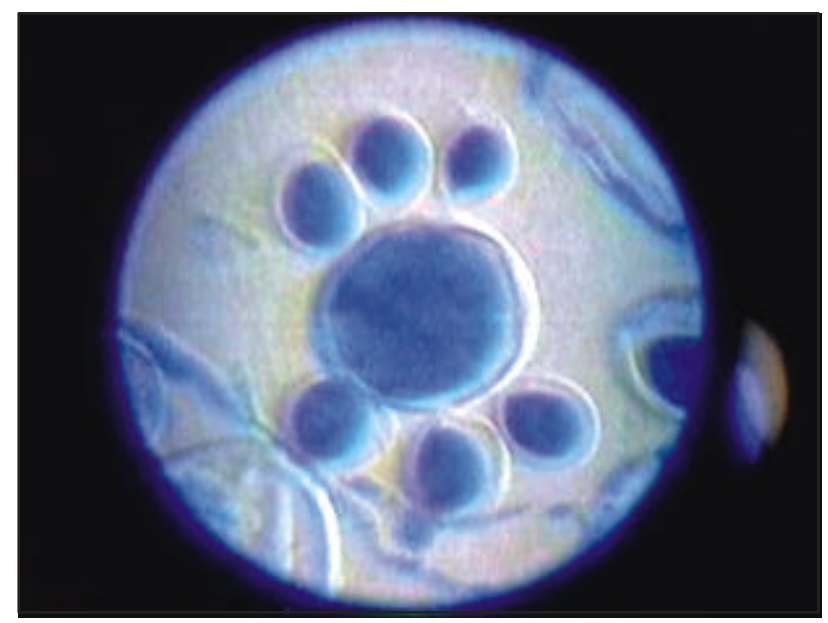

Figura 11.-Paracoccidioides brasiliensis: Hongo dimórfico; tinción de Kane. Se visualiza macroconidia en forma de "timón de barco" en imagen tridimensional.

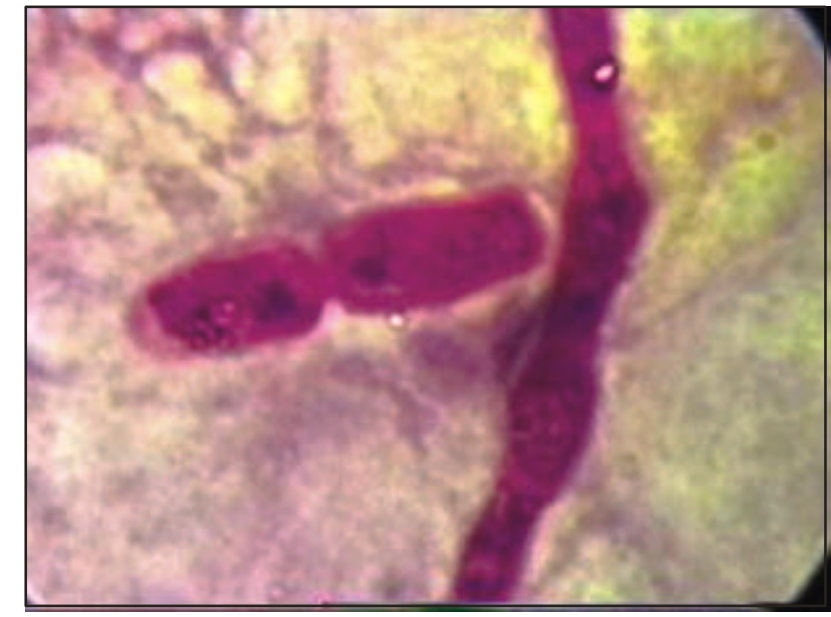

Figura 10.-Dermatofito:

Artrosporas en muestras de raspado de piel; tinción de Gueguen.

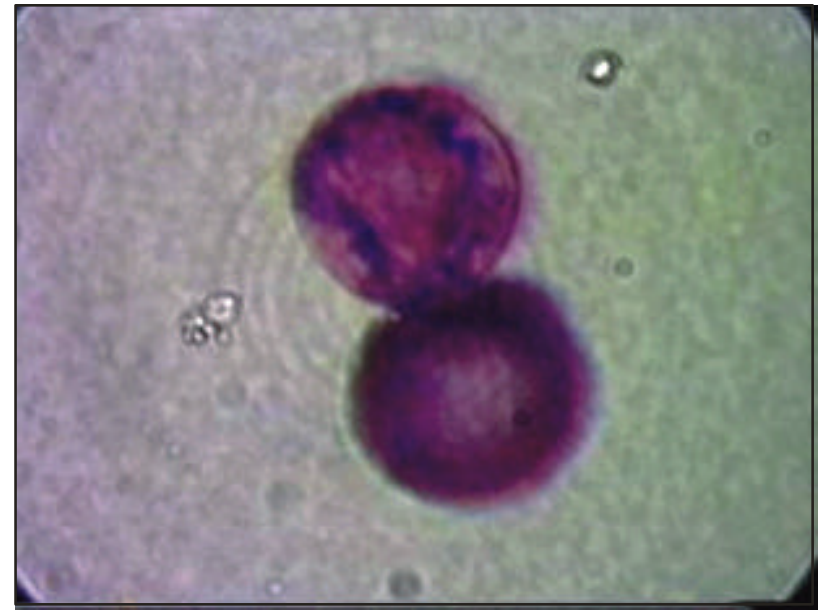

Figura 12.-Cryptosporidium parvum:

Protozoo coccidia, agente de diarrea principalmente en paciente inmunodeprimidos; tinción de Kinyoun.

Se observa dos oocistos de color rojo. 


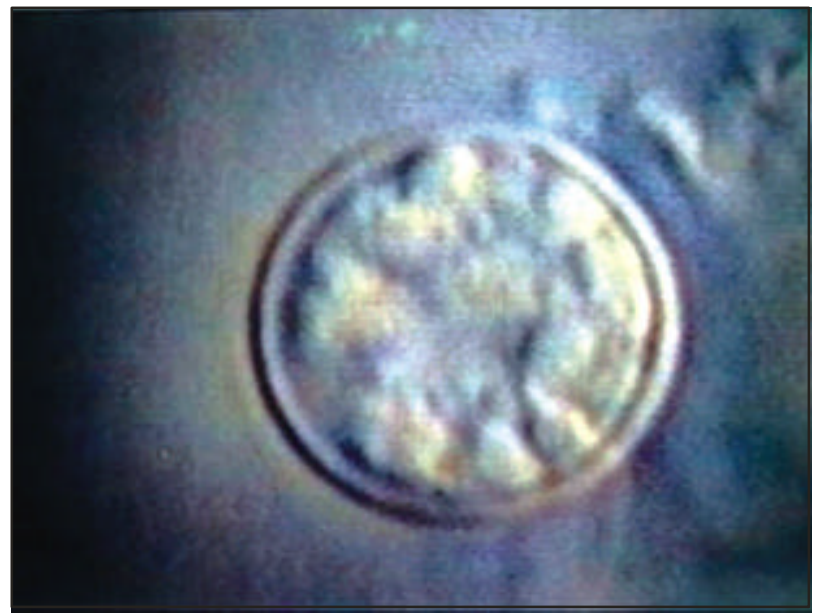

Figura 13.- Cyclospora cayetanensis: Oocisto en una preparación en fresco, sin colorear.

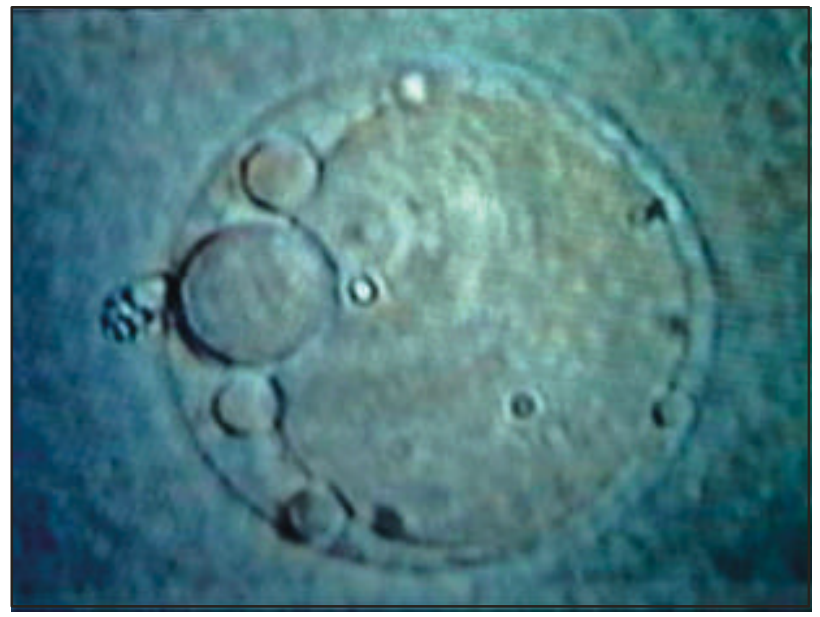

Figura 15.-Blastocystis hominis:

Forma vacuolada o de cuerpo central, en preparación en fresco, sin colorear.

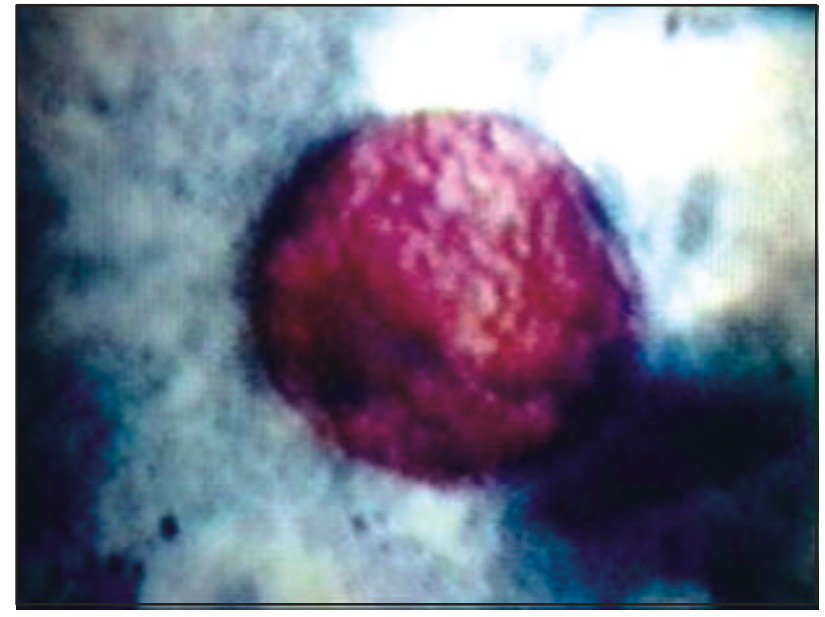

Figura 14.-Cyclospora cayetanensis:

Oocisto en una preparación con tinción de Kinyoun. Se observa el oocisto de color rojo.

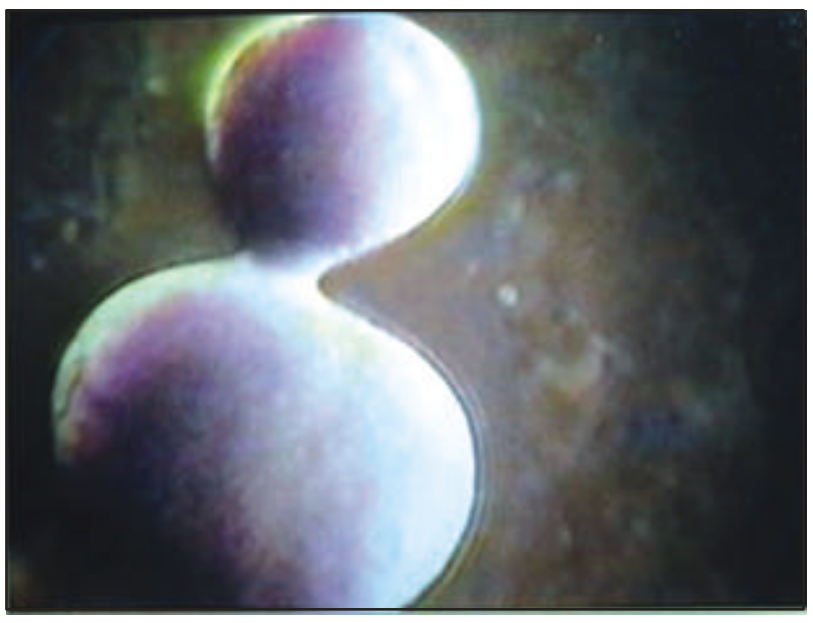

Figura 16.-Blastocystis hominis:

En forma de división gemante; en preparación en fresco, sin colorear. Se le visualiza en imagen tridimensional. 


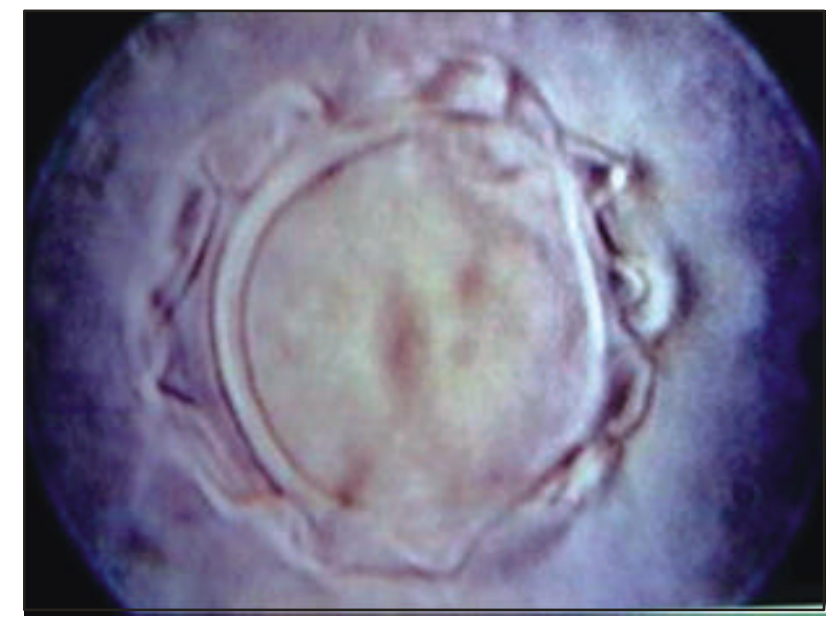

Figura 17.-Acanthamoeba sp.:

Oocisto en una preparación en montaje húmedo.

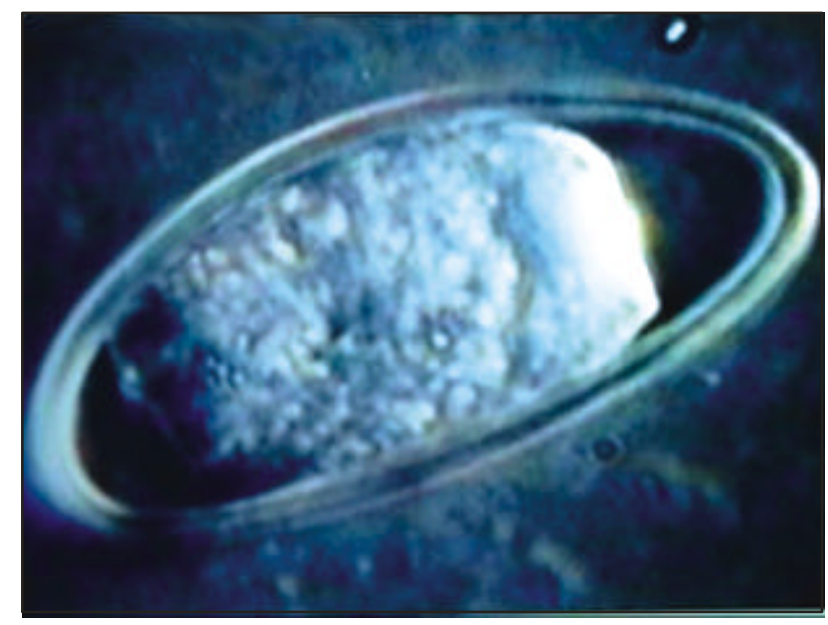

Figura 19.-Enterobius vermicularis:

Imagen tridimensional de un huevo embrionado.

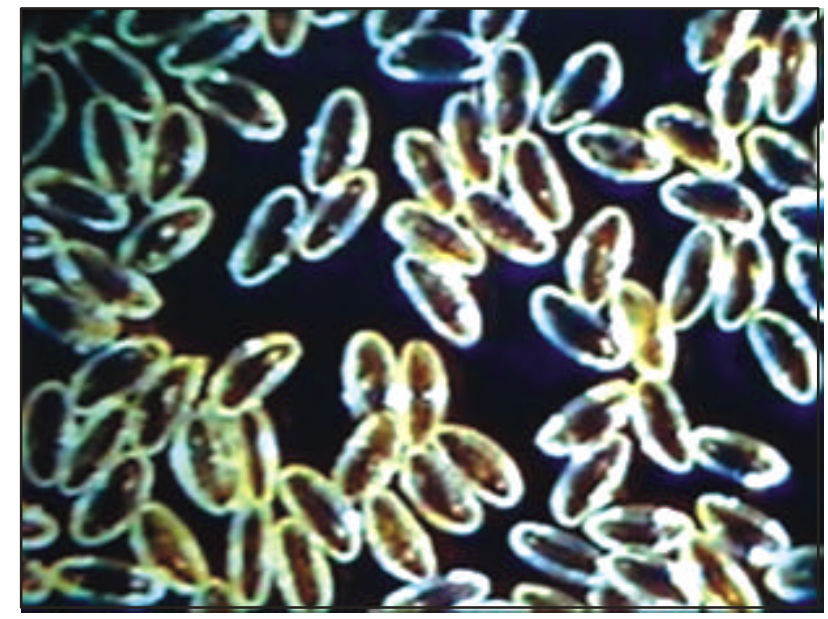

Figura 18.-Enterobius vermicularis: Numerosos huevos en fondo oscuro.

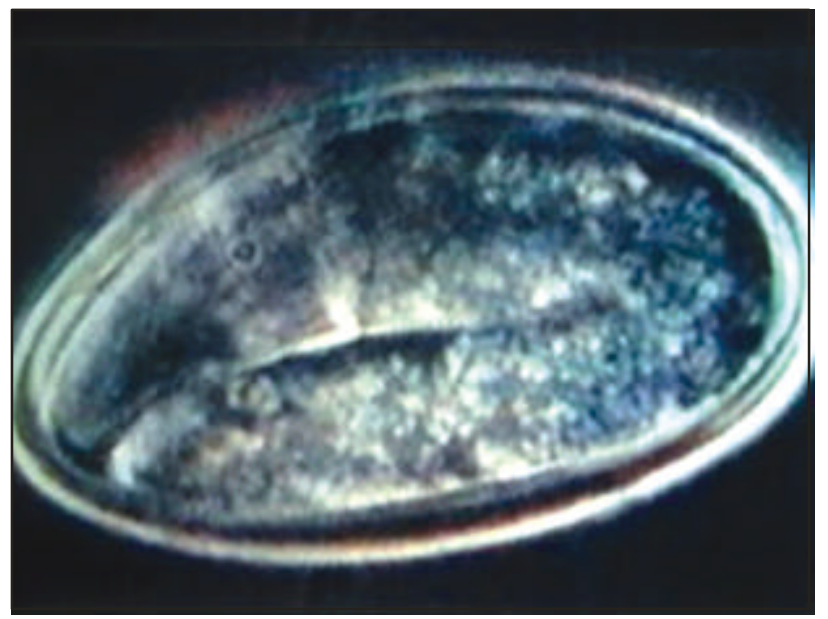

Figura 20.-Enterobius vermicularis: Imagen tridimensional de un huevo larvado. 


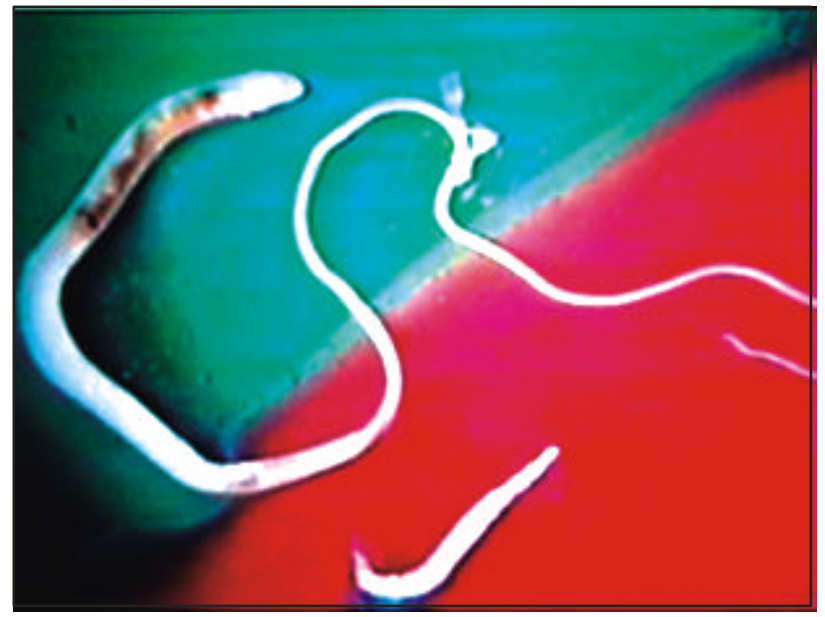

Figura 21.-Trichuris trichiura:

Parásito adulto hembra en la parte superior y Enterobius vermicularis en la parte inferior.

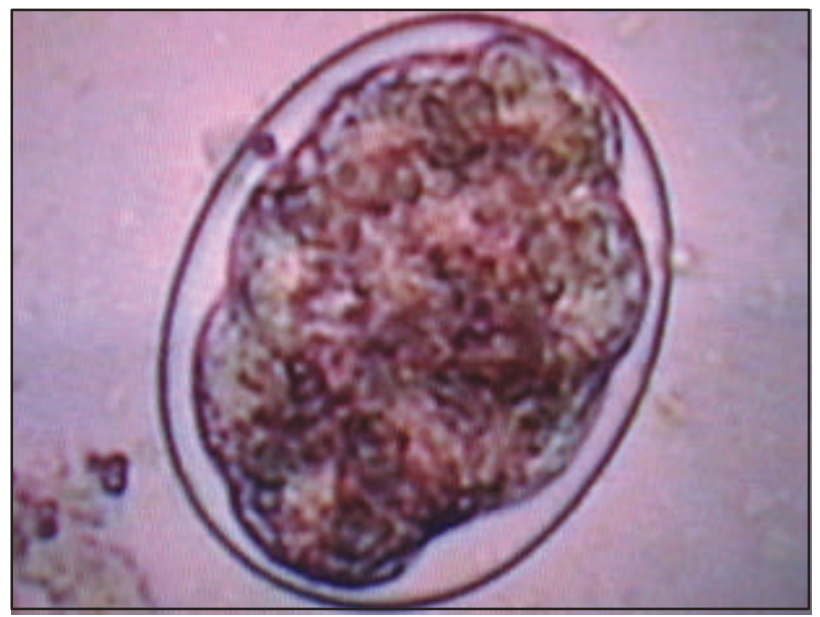

Figura 23.-Strongyloides stercoralis: Huevo, preparación en montaje húmedo.

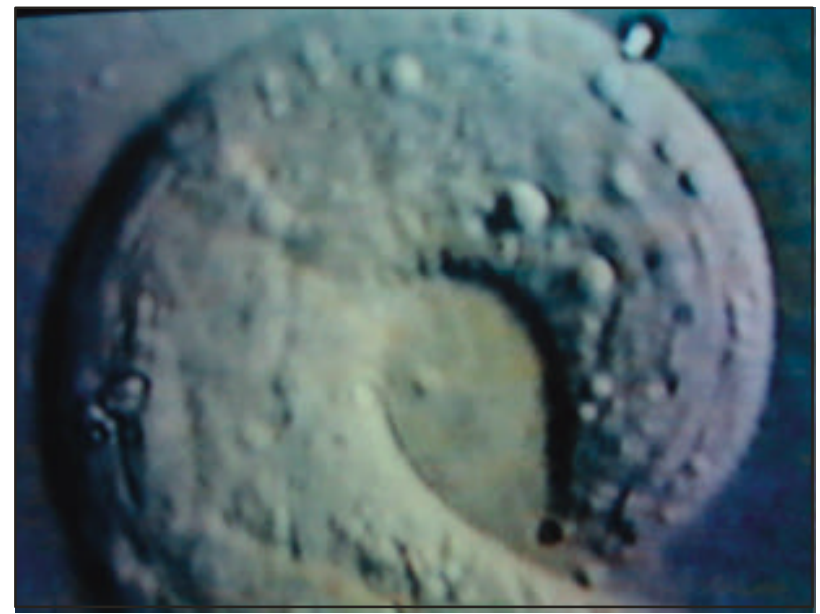

Figura 22.-Strongyloides stercoralis:

Porción cefálica de larva rhabditoide, en imagen tridimensional semejante a la que se obtiene con microscopio de barrido (scanning).

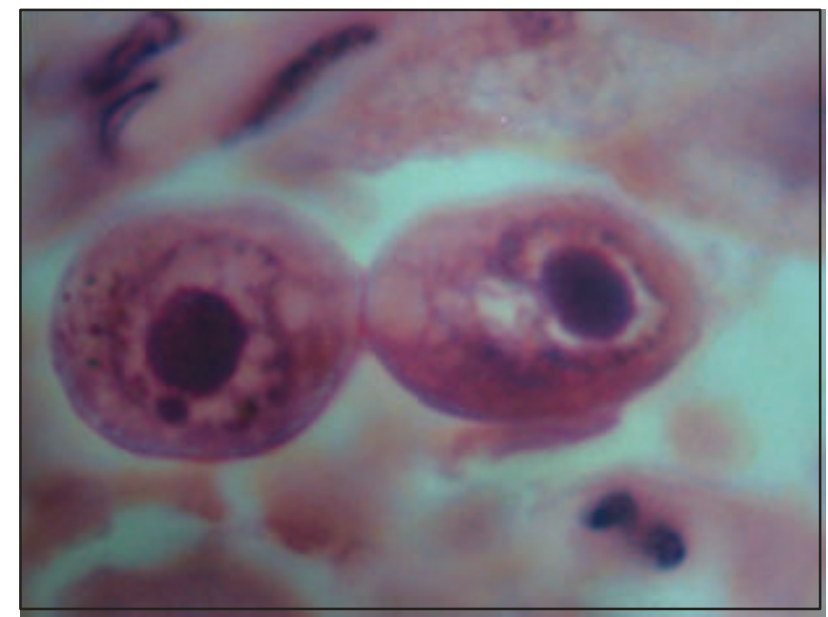

Figura 24.- Citomegalovirus:

En un niño fallecido con SIDA e infección por citomegalovirus. Corte histopatológico de pulmón; tinción de H.E. Se visualiza dos neumocitos con su núcleo y cuerpo de inclusión nuclear basófilo. 